\title{
Ciprofloxacin safety in paediatrics: a systematic review
}

\author{
Abiodun Adefurin, ${ }^{1}$ Helen Sammons, ${ }^{1}$ Evelyne Jacqz-Aigrain, ${ }^{2}$ Imti Choonara ${ }^{1}$
}

- Supplementary

appendices 1 and 2 are published online only. To view these files please visit the journal online (http://adc.bmj. com)

${ }^{1}$ Academic Division of Child Health, University of Nottingham, Derbyshire Children's Hospital, Derby, UK 2Department of Pediatric Pharmacology and Pharmacogenetics, Clinical Investigation Center (CIC), 9202 INSERM, Hôpital Robert Debré, Paris, France

\section{Correspondence to} Imti Choonara, Academic Division of Child Health, University of Nottingham, Derbyshire Children's Hospital, Derby DE22 3DT UK: imti.choonara@nottingham. ac.uk

\section{Accepted 8 June 2011} Published Online First 23 July 2011

This paper is freely available online under the BMJ Journals unlocked scheme, see http:// adc.bmi.com/info/unlocked.dtl

\section{ABSTRACT}

Objective To determine the safety of ciprofloxacin in paediatric patients in relation to arthropathy, any other adverse events (AEs) and drug interactions.

Methods A systematic search of MEDLINE, EMBASE, CINAHL, CENTRAL and bibliographies of relevant articles was carried out for all published articles, regardless of design, that involved the use of ciprofloxacin in any paediatric age group $\leq 17$ years. Only articles that reported on safety were included.

Results 105 articles met the inclusion criteria and involved 16184 paediatric patients. There were 1065 reported AEs (risk 7\%, $95 \% \mathrm{Cl} 3.2 \%$ to $14.0 \%$ ). The most frequent AEs were musculoskeletal AEs, abnormal liver function tests, nausea, changes in white blood cell counts and vomiting. There were six drug interactions (with aminophylline (4) and methotrexate (2)). The only drug related death occurred in a neonate who had an anaphylactic reaction. 258 musculoskeletal events occurred in 232 paediatric patients (risk 1.6\%, 95\% Cl $0.9 \%$ to $2.6 \%$ ). Arthralgia accounted for $50 \%$ of these. The age of occurrence of arthropathy ranged from 7 months to 17 years (median 10 years). All cases of arthropathy resolved or improved with management. One prospective controlled study estimated the risk of arthropathy as 9.3 (OR 95\% Cl 1.2 to 195). Pooled safety data of controlled trials in this review estimated the risk of arthropathy as 1.57 (OR 95\% Cl 1.26 to 1.97).

Conclusion Musculoskeletal AEs occur due to ciprofloxacin use. However, these musculoskeletal events are reversible with management. It is recommended that further prospective controlled studies should be carried out to evaluate the safety of ciprofloxacin, with particular focus on the risk of arthropathy.

\section{INTRODUCTION}

The first quinolone discovered was nalidixic acid in 1962, as a by-product of antimalarial research. Its use was limited due to its narrow spectrum of antibacterial activity, low serum levels and toxicity issues. ${ }^{1}$ Fluorination of the quinolone nucleus at position 6 resulted in introduction of second, third and fourth generations of fluoroquinolones, with ciprofloxacin in 1987 as a second generation fluoroquinolone. ${ }^{2}$ Ciprofloxacin is a broad spectrum, bactericidal antibiotic which acts by binding two of the four topoisomerases of bacteria. ${ }^{3}$

The use of ciprofloxacin and fluoroquinolones as a group in paediatric patients has been limited due to arthropathy noticed in weight bearing joints of juvenile animals. Cartilage damage caused by quinolones (nalidixic, oxolinic and pipemidic acids) was first reported in juvenile animals (beagle dogs 4-12 months of age). ${ }^{4}$ The arthropathy caused by quinolones has also been demonstrated

\section{What is already known on this topic}

- Ciprofloxacin is a broad spectrum, bactericidal antibiotic with good tissue penetration.

- Ciprofloxacin and fluoroquinolones as a group, cause arthropathy in weight bearing joints of juvenile animals.

- The use of ciprofloxacin in paediatrics has been limited due to the possibility of arthropathy.

\section{What this study adds}

- Musculoskeletal adverse events (AEs) are the most frequently reported $\mathrm{AEs}$ in paediatric patients after ciprofloxacin use.

- All musculoskeletal AEs reported in the literature have been reversible following withdrawal of ciprofloxacin.

in other animal species such as mice, ${ }^{5}$ dogs, ${ }^{6}$ rats $^{7}$ and rabbits, ${ }^{8}$ and in in-vitro animal culture ${ }^{9}$ and in-vitro human cell culture. ${ }^{10}$

Due to the good antibacterial activity and tissue penetration, different investigators have used ciprofloxacin in paediatric patients. The occurrence of arthropathy is uncertain. Other adverse drug reactions and drug interactions have been reported with ciprofloxacin use in adults. ${ }^{11}$ However, the drug toxicity profile has not been ascertained in paediatric use. This systematic review aims to pool together all the safety data about use of ciprofloxacin in paediatrics, with a critical look at the occurrence of arthropathy.

\section{METHODS}

\section{Search strategy}

We searched MEDLINE (1950 to November 2009), EMBASE (1950 to November 2009), the Cochrane database for systematic reviews, the Cochrane Central Register of Controlled Trials (CENTRAL), and the Cumulative Index to Nursing and Allied Health Literature (CINAHL) for any study with documented involvement of any paediatric age group (0-17 years) that used ciprofloxacin as intervention via any route of administration and for any disease condition. There was no restriction on the type of study that was included, language of publication or inclusion of abstracts. Any study with involvement of a paediatric age group participant taking at least a single dose of ciprofloxacin was included. This was necessary to 
ascertain the extent of use of ciprofloxacin in paediatrics and to be able to pool any documented adverse events (AEs) involving any paediatric age group. Hand searching of references of articles was also done. Studies that involved only adults were excluded. Search terms comprised both subject headings and free text words. These included terms relating to ciprofloxacin or quinolones or fluoroquinolones; adverse effects or adverse drug reactions or side effects; arthropathy or cartilage toxicity or chondrotoxicity or joint damage; and pharmacokinetics (see online supplementary appendix 1).

\section{Outcome measures}

The prespecified outcomes were as follows:

1. Occurrence of arthropathy specified as joint pain, joint swelling, reduced movement of joint or radiographic evidence of joint damage and any other musculoskeletal AE.

2. Occurrence of any other AEs from ciprofloxacin use.

3. Occurrence of drug-drug interactions due to ciprofloxacin use.

4. Death due to adverse drug reaction from ciprofloxacin use.

\section{Data collection and analysis}

The relevant data were extracted onto the data extraction form. Only studies that reported on the number of paediatric patients within each study and reported on safety of ciprofloxacin in the paediatric patients were analysed. Participants in the study were grouped into the following paediatric age groups: preterm neonates ( $<36$ weeks gestation, $0-27$ days); full-term neonates ( $0-27$ days, $>37$ weeks gestation); infants and toddlers (28 days to 23 months); children (2-11 years); and adolescents (12-17 years). AEs were classified according to the WHO adverse reaction terminology classification into one of the several organ systems, and were further analysed to determine which AEs actually occurred in any of the paediatric age groups (see online supplementary appendix 2). The arthropathy reports were analysed for causality in relation to the time of exposure to the drug, presence of other disease and medications. ${ }^{12}$ Details of the arthropathy included the time to development of arthropathy following ciprofloxacin use; the time to follow-up of patients after use of ciprofloxacin; method of detecting arthropathy in patients; and any management of the arthropathy. A descriptive analysis of extracted data was performed. Statistical analysis was carried out using SPSS V.18 and GraphPad software.

\section{RESULTS}

We identified a total of 105 studies (figure 1), the majority of which were case series or case reports ${ }^{13-117}$ (table 1). However, most of the patients (88\%) were within case series or cohort studies.

\section{Dosage and formulations}

The dose ranged from 3.1 to $93.8 \mathrm{mg} / \mathrm{kg} /$ day (oral) and 3.2 to $76.9 \mathrm{mg} / \mathrm{kg} / \mathrm{day}$ (intravenous). ${ }^{68}$ The usual dose in at least $60 \%$ of studies was $10-30 \mathrm{mg} / \mathrm{kg} /$ day in two divided doses for both oral and intravenous administration. The duration of ciprofloxacin ranged from single dose (pharmacokinetic studies, therapy for cholera and prophylaxis for meningococcal disease) to 880 days (a 12 -year-old with osteomyelitis). ${ }^{68}$ The median duration of use was 14 days.

Due to the lack of a commercially available paediatric formulation, various formulations were used, including a prepared suspension from granular ciprofloxacin, ${ }^{16} 1866$ tablets, ${ }^{19}$ 25448198115 ground tablets, ${ }^{82}$ a suspension formulation from Bayer, ${ }^{13} 22$ pulverised tablets with sweet liquid, ${ }^{42}$ and tablets crushed and mixed in cherry syrup. ${ }^{70}$ Topical ciprofloxacin was administered as drops to the eyes/ears.

\section{Analysis of safety}

All reported AEs were analysed together (table 2). Sixty-eight studies reported AEs, while 37 studies reported no AEs. In total, 16184 paediatric patients were exposed to ciprofloxacin and there were 1065 reported AEs. This gave an estimated risk of $7 \mathrm{AEs}$ in every 100 patients $(7 \%, 95 \%$ CI $3.2 \%$ to $14.0 \%)$, or $1 \mathrm{AE}$ in every 14 patients receiving ciprofloxacin.

The most frequent AEs were musculoskeletal problems, abnormal liver function tests, nausea, changes in white blood cell counts and vomiting (table 2). These are pooled safety data of reported AEs by individual authors of the studies in our review. There was no dose dependent or duration dependent risk of toxicity.

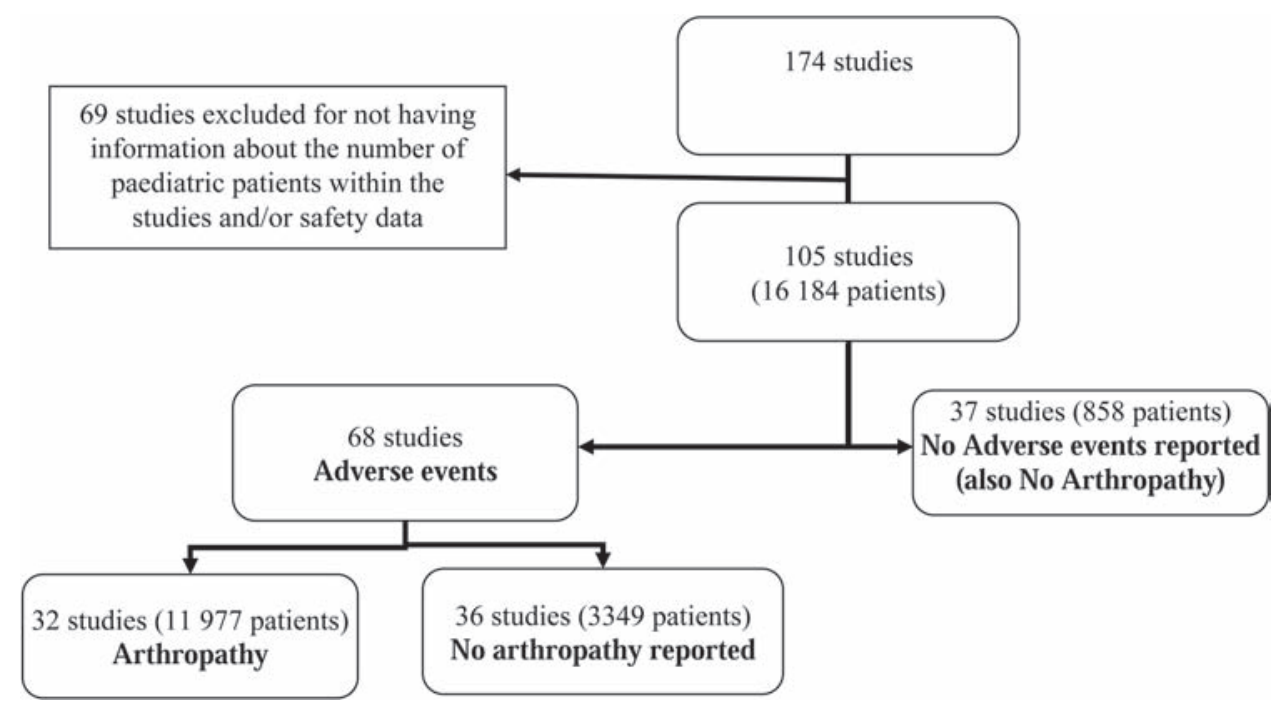

Figure 1 Algorithm of the analysis of the studies in the systematic review. 
Table 1 Summary of 105 studies that reported on safety of ciprofloxacin in paediatrics

\begin{tabular}{|c|c|c|}
\hline Type of study & Frequency $(\mathrm{N}=105)$ & $\begin{array}{c}\text { Number of patients } \\
(\mathrm{N}=16 \mathrm{184})\end{array}$ \\
\hline Case series & 46 & 8876 \\
\hline Case report & 24 & 24 \\
\hline RCT & 15 & 1787 \\
\hline Cohort study & 12 & 5368 \\
\hline Pharmacokinetic & 5 & 79 \\
\hline Non-RCT & 3 & 50 \\
\hline Route of administration & Frequency $(\mathrm{N}=105)$ & $\begin{array}{l}\text { Number of patients } \\
\qquad(\mathrm{N}=16 \mathrm{184})\end{array}$ \\
\hline Oral & 39 & 1871 \\
\hline Intravenous & 25 & 329 \\
\hline Intravenous and oral & 19 & 6489 \\
\hline Not reported & 16 & 6905 \\
\hline Topical & 6 & 590 \\
\hline Age group & Frequency $(\mathrm{N}) *$ & Number of patients ${ }^{\dagger}$ \\
\hline Children & 67 & NA \\
\hline Adolescents & 53 & NA \\
\hline Infants & 40 & NA \\
\hline Preterm neonates & 19 & NA \\
\hline Neonates (GA not stated) & 18 & NA \\
\hline Term Neonates & 9 & NA \\
\hline
\end{tabular}

*Total number of studies for age group is not 105 studies because multiple age groups were included within some studies.

${ }^{\dagger}$ The number of patients in each age group could not be ascertained because most studies involved more than one age group and the number within each age group was not reported.

$\mathrm{GA}$, gestational age; NA, not available; RCT, randomised controlled trial.

Drug related death occurred in a neonate who experienced an anaphylactic reaction following intravenous ciprofloxacin. An additional 23 paediatric patients had to discontinue ciprofloxacin due to serious AEs (table 3).

There were six drug interactions with ciprofloxacin. Four patients had drug interactions with aminophylline ${ }^{47}$ (two patients were irritable/restless, one had tremors and one had hot flushes). Two patients had delayed elimination of methotrexate. ${ }^{55}$ However, there was no drug interaction with aminophylline in seven preterm babies. ${ }^{21}$

\section{Arthropathy}

Thirty-two studies reported arthropathy, while 73 studies reported no arthropathy (37 studies reporting no AEs +36 studies of those reporting AEs that reported no arthropathy). There was no evidence that dose or duration had an effect on arthropathy.

In total, 16184 paediatric patients were exposed to ciprofloxacin; 258 musculoskeletal events occurred in 232 paediatric patients (some patients had more than one musculoskeletal $\mathrm{AE})$. This gave an estimated risk of 16 musculoskeletal AEs per 1000 patients receiving ciprofloxacin $(1.6 \%, 95 \%$ CI $0.9 \%$ to $2.6 \%$ ) or one musculoskeletal AE in every 62.5 patients. A summary of the reported symptoms and/or signs of arthropathy is presented in table 4. Only 10 of the 32 studies gave detailed information regarding time and onset, duration of follow-up, method of detecting arthropathy and management.

The youngest documented case of arthropathy was in a 7-month-old infant. ${ }^{60}$ Age of occurrence was documented in 47 paediatric patients; median age was 10 years. The time to follow-up of the patients after use of ciprofloxacin was 1 week to 50 months. ${ }^{80} 109$ Of 47 studies reporting the time
Table 2 Summary of reported adverse events (AEs) from 68 studies

\begin{tabular}{|c|c|}
\hline AEs & Frequency \\
\hline Musculoskeletal & $232^{*}$ \\
\hline Abnormal liver function tests & 139 \\
\hline Nausea & 75 \\
\hline Blood cell count derangements & 57 \\
\hline Vomiting & 56 \\
\hline Rash & 51 \\
\hline Injection site reaction & 47 \\
\hline Headache & 41 \\
\hline Hearing/eye associated AEs & 42 \\
\hline Abdominal pain/discomfort & 38 \\
\hline Diarrhoea & 36 \\
\hline Psychiatric disorders & 18 \\
\hline Dizziness/decreased consciousness & 13 \\
\hline Pruritus & 2 \\
\hline Irritability/anxiety/nervousness & 12 \\
\hline Photosensitivity & 10 \\
\hline Acute renal failure/impaired renal function & 9 \\
\hline Abdominal distension & 8 \\
\hline Allergy/anaphylactoid reaction & 7 \\
\hline Oral cavity abnormalities & 6 \\
\hline Bleeding & 6 \\
\hline Hemiparesis/hypotonia/hyperreflexia/ataxia & 5 \\
\hline Fever/hot flushes & 5 \\
\hline Rigors/shivering/tremors & 4 \\
\hline Interstitial nephritis & 4 \\
\hline Others ${ }^{\dagger}$ & 34 \\
\hline Not specified ${ }^{\ddagger}$ & 98 \\
\hline Total & 1065 \\
\hline
\end{tabular}

*232 patients had 258 musculoskeletal events.

${ }^{\dagger}$ Others include AEs which occurred once, twice or thrice only. These include seizures, haemolytic uraemic syndrome, pseudomembranous colitis, gastro-oesophageal reflux disease, urinary retention, greenish discolouration of teeth, malaise, weight loss, dysuria, heart failure, sinoatrial nodal arrest and tachycardia.

${ }^{\ddagger}$ Not specified AEs reported as unknown.

to follow-up of the patients, 31 studies (66\%) followed up for an average time of $\geq 90$ days. The time to development of any form of arthropathy was reported in 12 studies and ranged from 15 min to 30 days (median 6 days). ${ }^{73} 81$ There were three additional cases of arthralgia that occurred on the first day of treatment. ${ }^{16} 101$ Management included continuation of drug use, discontinuation of drug with/without rechallenge, use of analgesics to relieve arthralgia, dose reduction or a combination of any of these measures. All cases of arthropathy with report on management resolved or improved. However, there was a report of arthralgia remaining unchanged in 1 out of 31 reported arthralgia cases in a study. However, we are not certain if any management was instituted or for how long the arthralgia persisted. ${ }^{74}$

Arthralgia accounted for 130 (50\%) events. Four patients discontinued therapy due to arthralgia, which resolved in three patients (no report of the outcome in the last patient). ${ }^{47} 68$ Radiological confirmation of arthropathy using MR1 was positive in two studies involving six cystic fibrosis patients, who had joint effusions, abnormal thickness of articular cartilage, non-homogeneous structure of cartilage or altered two-layer appearance of cartilage. ${ }^{79} 91$ In addition to clinical examination and radiological investigation, seven studies (531 cases and 674 controls) investigated the effects of ciprofloxacin on growth of patients after following up the patients for 6-50 months. ${ }^{28} 32336375109116$ None of these studies found 
Table 3 Summary of serious adverse events necessitating withdrawal and/or discontinuation of therapy

\begin{tabular}{lc}
\hline AE & $\begin{array}{c}\text { Number of } \\
\text { patients }(\mathbf{n}=\mathbf{2 3} \text { ) }\end{array}$ \\
\hline Rash & 5 \\
Arthralgia & 4 \\
Vomiting and diarrhoea & 2 \\
Allergy & 2 \\
Anaphylactoid reaction & 2 \\
Epistaxis & 1 \\
Angioneurotic oedema & 1 \\
Cardiac failure & 1 \\
Sinus nodal arrest & 1 \\
Toxic megacolon & 1 \\
Nausea & 1 \\
Interstitial nephritis & 1 \\
Benign intracranial hypertension & 1
\end{tabular}

Table 4 Summary of reported musculoskeletal events from 32 studies

\begin{tabular}{lc}
\hline Musculoskeletal events & Frequency (\%) \\
\hline Arthralgia & $130(50.0)$ \\
Tendon or joint disorder & $48(19.0)$ \\
Reduced movement/stiffness & $39(15.0)$ \\
Joint swelling & $8(3.0)$ \\
Radiological confirmed arthropathy & $6(2.3)$ \\
Myalgia & $4(1.6)$ \\
Arthritis & $3(1.2)$ \\
Pain in extremity & $1(0.4)$ \\
Osteitis & $1(0.4)$ \\
Unknown & $18(7.0)$ \\
Total & $258^{*}(100)$ \\
\hline
\end{tabular}

*258 musculoskeletal events occurred in 232 patients.

any significant difference in growth of the ciprofloxacin exposed patients compared with the control arm.

The majority of the musculoskeletal events (223, 86\%) were classified as possibly related to ciprofloxacin. Rechallenge with ciprofloxacin was done in eight patients, but was positive in only a 9-year-old cystic fibrosis patient who had received $17 \mathrm{mg} / \mathrm{kg} /$ day for 15 days and noticed arthralgia of elbow and knees on the sixth day post-therapy. ${ }^{83} 91101$ No information was given about how long arthralgia lasted on rechallenge and if any management was instituted.

\section{Controlled studies}

Only two studies estimated the risk of development of arthropathy in paediatric patients receiving ciprofloxacin compared to a control group. A prospective cohort study of 264 cases and 249 controls matched for age and presence of cystic fibrosis, followed up patients for 15 days after the last dose of treatment. ${ }^{101}$ An estimated crude OR for musculoskeletal AEs in the fluoroquinolone group (ciprofloxacin, ofloxacin and perfloxacin) compared to other antibiotics was 9.3 (95\% CI 1.2 to $195, p=0.02)$. Considering cystic fibrosis patients alone within the same study (approximately 90 patients in each group), the OR for musculoskeletal AEs in the fluoroquinolone group compared to other antibiotics was 1.2 (95\% CI 0.1 to $35, p=0.99)$. The ORs estimated were not adjusted for possible influence of age and sex.
Second, a retrospective cohort study using a pharmacy database of patients exposed to fluoroquinolones and azithromycin, checked for potential joint or tendon disorder diagnosed within 60 days of exposure to drug. ${ }^{103}$ The joint or tendon disorders were verified from medical records of the patients by three blinded specialists. The study had over 4500 patients receiving ciprofloxacin and over 1500 patients receiving ofloxacin compared to over 15000 patients receiving azithromycin. The estimated RR for verified tendon or joint disorder for ciprofloxacin was 1.04 (95\% CI 0.72 to 1.51) and for ofloxacin was 1.04 (95\% CI 0.55 to 1.84$)$. The age and sex adjusted RR were 1.08 (95\% CI 0.74 to 1.58$)$ for ciprofloxacin and 1.13 (95\% CI 0.63 to 2.03 ) for ofloxacin.

Safety data of all randomised controlled trials, non-randomised controlled trials and cohort studies in our review were pooled together. Analysis of 23 controlled studies (7 controlled studies were excluded because ciprofloxacin or another fluoroquinolone was administered in the comparator arm) comprising 6481 cases and 17441 controls showed that there is a $57 \%$ increased risk of arthropathy in patients who received ciprofloxacin compared to the comparator arm (OR 1.57, 95\% CI 1.26 to 1.97).13 15-19 28-33 63757679101103105109111112116 Further analysis of five controlled studies that included only cystic fibrosis patients (227 cases and 391 controls) estimated a $67 \%$ increased risk of arthropathy (OR 1.67, 95\% CI 1.13 to 2.45). ${ }^{17} 1979101105$

\section{DISCUSSION}

Our systematic review about the safety of ciprofloxacin is the first review that has pooled together all reported suspected AEs due to ciprofloxacin use in paediatric patients. Ciprofloxacin is contraindicated in paediatrics because juvenile animals developed arthropathy after use. ${ }^{4}$ However, our review has identified over 16000 children who have received ciprofloxacin. It is likely that the number of children who have received ciprofloxacin in practice is significantly greater than this.

Our review confirms that musculoskeletal toxicity is the most frequently reported AE following the use of ciprofloxacin. There is, however, a wide range of toxicity that has been reported and it is important to recognise that, like all antiinfective agents, ciprofloxacin can be associated with a broad spectrum of AEs. The toxicity profile in table 2 is pooled safety data of reported suspected AEs by individual authors; however, these AEs may not be adverse drug reactions in all cases. From our review, there is an estimated risk of one musculoskeletal AE in every 62.5 patients, and a $57 \%$ increased risk of arthropathy in patients exposed to ciprofloxacin. The musculoskeletal AEs appear reversible with management.

The term arthropathy has been used broadly for various musculoskeletal AEs. Juvenile animals were noted to have gait stiffness, particularly in the hind limbs; reluctance to rise from a sitting, lateral or sternal recumbence position; exudation of synovial fluid; and blistering and ulcerative erosions of articular cartilage in the limb joints. ${ }^{4} 118$ However, our review suggested that arthralgia was the commonest symptom of arthropathy $(50 \%)$ in paediatric patients, affecting mostly the knee joint. Tendon or joint disorders and reduced movement also accounted for a significant proportion of arthropathy cases (19\% and $15 \%$, respectively). Although the specific tendon disorder could not be ascertained, tendinitis or tendon rupture could be implied as this represents the most frequent presentations in the literature. ${ }^{119-121}$ The only specific report of tendon disorder in our review was a case of Achilles tendinitis in a patient (age not specified). ${ }^{106}$ Tendon disorders have been 
thought to occur more frequently in patients over 60 years. ${ }^{122}$ However, our review suggests it is also reported in paediatric patients, and clinicians should be aware of such possibility.

Various molecular mechanisms have been postulated for arthropathy, such as inhibition of synthesis of collagen and glycosaminoglycans, inhibition in mitochondrial function resulting in generation of free radicals and oxidative stress or chelation of magnesium ions, all culminating in cartilage and tendon damage. ${ }^{5} 123$

There appear to be differences in features of arthropathy in animals compared to humans. Two studies reported on the histopathology of the articular cartilage of three patients at postmortem examination, but no arthropathic lesions were noted. ${ }^{64} 91$ However, animal studies showed exudation of synovial fluid, blistering and ulcerative erosion of articular cartilage at postmortem examination, even after clinical recovery. ${ }^{4}$

Animal studies have suggested that arthropathy occurs earlier in younger animals. ${ }^{118}$ However, our review showed a median age of 10 years (range 7 months to 17 years) among 47 age documented paediatric patients. Although most of the studies included in our review involved children (2-11 years), at least 389 neonates were exposed, with none developing musculoskeletal AEs. The differences in growth between animals and humans have been suggested as a possible explanation for such differences. The number, location and time of appearance of secondary ossification centres vary between animal species and humans.

Arthropathy in animals appears to be dose related, with increased risk in higher doses and after longer duration of treatment. ${ }^{124} 125$ However, our data does not point to any dose dependent or duration dependent relationship in humans.

In conclusion, our review identified only one prospective cohort study showing an increased risk of arthropathy, and we estimated an increased risk in those exposed to ciprofloxacin. The concern of arthropathy in paediatric patients, based on studies in juvenile animals is therefore appropriate; however, the risk of arthropathy is relatively low and reversible with management. The risk of ciprofloxacin-induced arthropathy needs to be considered in relation to the benefits of using ciprofloxacin in children with acute infections. The role of ciprofloxacin in paediatric and neonatal sepsis can only be clarified by further prospective studies evaluating both the benefit and the risk of toxicity, with a particular focus on the risk of arthropathy.

Acknowledgements This work is part of the TINN network (Collaborative Project), supported by the European Commission under the Health Cooperation Work Programme of the 7th Framework Programme (grant agreement number 223614).

Funding TINN project, an FP7 project sponsored by the European Commission.

Competing interests None.

Provenance and peer review Not commissioned; externally peer reviewed.

\section{REFERENCES}

1. Van Bambeke F, Michot JM, Van Eldere J, et al. Quinolones in 2005: an update. Clin Microbiol Infect 2005;11:256-80.

2. Committee on Infectious Diseases. The use of systemic fluoroquinolones. Pediatrics 2006;118:1287-92

3. Gendrel D, Chalumeau M, Moulin F, et al. Fluoroquinolones in paediatrics: a risk for the patient or for the community? Lancet Infect Dis 2003;3:537-46.

4. Ingham B, Brentnall DW, Dale EA, et al. Arthropathy induced by antibacterial fused N-alkyl-4-pyridone-3-carboxylic acids. Toxicol Lett 1977;1:21-6.

5. Simonin MA, Gegout-Pottie P, Minn A, et al. Proteoglycan and collagen biochemical variations during fluoroquinolone-induced chondrotoxicity in mice. Antimicrob Agents Chemother 1999;43:2915-21.
6. Gough A, Barsoum NJ, Mitchell L, et al. Juvenile canine drug-induced arthropathy: clinicopathological studies on articular lesions caused by oxolinic and pipemidic acids. Toxicol Appl Pharmacol 1979;51:177-87.

7. Pfister K, Mazur D, Vormann J, et al. Diminished ciprofloxacin-induced chondrotoxicity by supplementation with magnesium and vitamin $\mathrm{E}$ in immature rats. Antimicrob Agents Chemother 2007;51:1022-7.

8. Machida M, Kusajima $\mathrm{H}$, Aijima $\mathrm{H}$, et al. Toxicokinetic study of norfloxacin-induced arthropathy in juvenile animals. Toxicol Appl Pharmacol 1990;105:403-12.

9. Egerbacher M, Wolfesberger B, Gabler C. In vitro evidence for effects of magnesium supplementation on quinolone-treated horse and dog chondrocytes Vet Pathol 2001;38:143-8.

10. Egerbacher M, Seiberl G, Wolfesberger B, et al. Ciprofloxacin causes cytoskeletal changes and detachment of human and rat chondrocytes in vitro. Arch Toxicol 2000;73:557-63.

11. Ball P. Ciprofloxacin: an overview of adverse experiences. J Antimicrob Chemother 1986;18(Suppl D):187-93

12. Edwards IR, Aronson JK. Adverse drug reactions: definitions, diagnosis, and management. Lancet 2000;356:1255-9.

13. Saha D, Khan WA, Karim MM, et al. Single-dose ciprofloxacin versus 12-dose erythromycin for childhood cholera: a randomised controlled trial. Lancet 2005;366:1085-93.

14. Schaad UB, Wedgwood J, Ruedeberg A, et al. Ciprofloxacin as antipseudomona treatment in patients with cystic fibrosis. Pediatr Infect Dis J 1997;16:106-11; discussion 123-6.

15. Chaudhari S, Suryawanshi P, Ambardekar S, et al. Safety profile of ciprofloxacin used for neonatal septicemia. Indian Pediatr 2004;41:1246-51.

16. Leibovitz E, Janco J, Piglansky L, et al. Oral ciprofloxacin vs. intramuscular ceftriaxone as empiric treatment of acute invasive diarrhea in children. Pediatr Infect Dis J 2000;19:1060-7.

17. Church DA, Kanga JF, Kuhn RJ, et al. Sequential ciprofloxacin therapy in pediatric cystic fibrosis: comparative study vs. ceftazidime/tobramycin in the treatment of acute pulmonary exacerbations. The Cystic Fibrosis Study Group. Pediatr Infect Dis J 1997:16:97-105; discussion 123-6.

18. Salam MA, Dhar U, Khan WA, et al. Randomised comparison of ciprofloxacin suspension and pivmecillinam for childhood shigellosis. Lancet 1998;352:522-7.

19. Richard DA, Nousia-Arvanitakis S, Sollich V, et al. Oral ciprofloxacin vs. intravenous ceftazidime plus tobramycin in pediatric cystic fibrosis patients: comparison of antipseudomonas efficacy and assessment of safety with ultrasonography and magnetic resonance imaging. Cystic Fibrosis Study Group. Pediatr Infect Dis J 1997:16:572-8.

20. Zimbabwe, Bangladesh, South Africa (Zimbasa) Dysentery Study Group. Multicenter, randomized, double blind clinical trial of short course versus standard course oral ciprofloxacin for Shigella dysenteriae type 1 dysentery in children. Pediatr Infect Dis J 2002;21:1136-41.

21. Aggarwal P, Dutta S, Garg SK, et al. Multiple dose pharmacokinetics of ciprofloxacin in preterm babies. Indian Pediatr 2004;41:1001-7.

22. Peltola H, Ukkonen P, Saxén H, et al. Single-dose and steady-state pharmacokinetics of a new oral suspension of ciprofloxacin in children. Pediatrics 1998;101:658-62.

23. Lipman J, Gous AG, Mathivha LR, et al. Ciprofloxacin pharmacokinetic profiles in paediatric sepsis: how much ciprofloxacin is enough? Intensive Care Med 2002;28:493-500.

24. Rubio TT, Miles MV, Lettieri JT, et al. Pharmacokinetic disposition of sequential intravenous/oral ciprofloxacin in pediatric cystic fibrosis patients with acute pulmonary exacerbation. Pediatr Infect Dis J 1997;16:112-17; discussion 123-6.

25. Redmond A, Sweeney L, MacFarland M, et al. Oral ciprofloxacin in the treatment of pseudomonas exacerbations of paediatric cystic fibrosis: clinical efficacy and safety evaluation using magnetic resonance image scanning. J Int Med Res 1998;26:304-12

26. Roland PS, Kreisler LS, Reese B, et al. Topical ciprofloxacin/dexamethasone otic suspension is superior to ofloxacin otic solution in the treatment of children with acute otitis media with otorrhea through tympanostomy tubes. Pediatrics 2004;113:e40-6

27. Roland PS, Anon JB, Moe RD, et al. Topical ciprofloxacin/dexamethasone is superior to ciprofloxacin alone in pediatric patients with acute otitis media and otorrhea through tympanostomy tubes. Laryngoscope 2003;113:2116-22.

28. Drossou-Agakidou V, Roilides E, Papakyriakidou-Koliouska P, et al. Use of ciprofloxacin in neonatal sepsis: lack of adverse effects up to one year. Pediatr Infect Dis J 2004:23:346-9.

29. Yousef AA, Fryer CJ, Chedid FD, et al. A pilot study of prophylactic ciprofloxacin during delayed intensification in children with acute lymphoblastic leukemia. Pediatr Blood Cancer 2004;43:637-43.

30. Cuevas LE, Kazembe P, Mughogho GK, et al. Eradication of nasopharyngeal carriage of Neisseria meningitidis in children and adults in rural Africa: a comparison of ciprofloxacin and rifampicin. J Infect Dis 1995;171:728-31.

31. Paganini H, Gómez S, Ruvinsky S, et al. Outpatient, sequential, parenteral-oral antibiotic therapy for lower risk febrile neutropenia in children with malignant 
disease: a single-center, randomized, controlled trial in Argentina. Cancer 2003;97:1775-80.

32. Doherty CP, Saha SK, Cutting WA. Typhoid fever, ciprofloxacin and growth in young children. Ann Trop Paediatr 2000;20:297-303.

33. Martell M, de Ben S, Weinberger M, et al. Growth and development in preterm infants receiving fluoroquinolones. J Perinat Med 1996;24:287-91.

34. Schaad UB, Wedgwood-Krucko J, Guenin K, et al. Antipseudomonal therapy in cystic fibrosis: aztreonam and amikacin versus ceftazidime and amikacin administered intravenously followed by oral ciprofloxacin. Eur J Clin Microbiol Infect Dis 1989;8:858-65.

35. Sen S, Goyal RS, Dev R. Ciprofloxacin in the management of multiple drug resistant typhoid fever. Indian Pediatr 1991;28:417-19.

36. Bavdekar A, Chaudhari M, Bhave S, et al. Ciprofloxacin in typhoid fever Indian J Pediatr 1991;58:335-9.

37. Wlazlowski J, Krzyzanska-Oberbek A, Sikora JP, et al. Use of the quinolones in treatment of severe bacterial infections in premature infants. Acta Pol Pharm 2000;57(Suppl):28-31

38. Naccari F, Salpietro DC, De Sarro A, et al. Tolerance and pharmacokinetics of ciprofloxacin in the chick. Preliminary experience in subjects of pediatric age with urinary tract infections (UTI). Res Commun Mol Pathol Pharmacol 1998;99:187-92.

39. Orenstein DM, Pattishall EN, Noyes BE, et al. Safety of ciprofloxacin in children with cystic fibrosis. Clin Pediatr (Phila) 1993;32:504-6.

40. Miller MS, Gaido F, Rourk MH, Jr, et al. Anaphylactoid reactions to ciprofloxacin in cystic fibrosis patients. Pediatr Infect Dis J 1991;10:164-5

41. Jawad AS. Cystic fibrosis and drug-induced arthropathy. Br J Rheumatol 1989:28:179-80.

42. Lang $\mathbf{R}$, Goshen S, Raas-Rothschild A, et al. Oral ciprofloxacin in the management of chronic suppurative otitis media without cholesteatoma in children: preliminary experience in 21 children. Pediatr Infect Dis J 1992;11:925-9.

43. Cheesbrough JS, Mwema Fl, Green SD, et al. Quinolones in children with invasive salmonellosis. Lancet 1991;338:127.

44. Dutta $\mathbf{P}$, Rasaily R, Saha MR, et al. Ciprofloxacin for treatment of severe typhoid fever in children. Antimicrob Agents Chemother 1993:37:1197-9.

45. Isaacs D, Slack MP, Wilkinson AR, et al. Successful treatment of Pseudomonas ventriculitis with ciprofloxacin. J Antimicrob Chemother 1986;17:535-8.

46. Lumbiganon P, Pengsaa K, Sookpranee T. Ciprofloxacin in neonates and its possible adverse effect on the teeth. Pediatr Infect Dis J 1991:10:619-20.

47. Karande SC, Kshirsagar NA. Adverse drug reaction monitoring of ciprofloxacin in pediatric practice. Indian Pediatr 1992;29:181-8.

48. Alfaham M, Holt ME, Goodchild MC. Arthropathy in a patient with cystic fibrosis taking ciprofloxacin. Br Med J (Clin Res Ed) 1987;295:699.

49. Ollé-Goig JE. Multiorgan involvement due to Salmonella typhi: case report. East Afr Med J 2006;83:693-5.

50. Toraman ZA, Yakupogullari Y. Carbapenemase-producing Pseudomonas aeruginosa and ciprofloxcacin use in neonatal intensive care units. J Hosp Infect 2003:54:164-5.

51. Arora RK, Gupta A, Joshi NM, et al. Multidrug resistant typhoid fever: study of an outbreak in Calcutta. Indian Pediatr 1992;29:61-6.

52. van den Oever $\mathbf{H L}$, Versteegh FG, Thewessen EA, et al. Ciprofloxacin in preterm neonates: case report and review of the literature. Eur J Pediatr 1998:157:843-5.

53. Bannon MJ, Stutchfield PR, Weindling AM, et al. Ciprofloxacin in neonata Enterobacter cloacae septicaemia. Arch Dis Child 1989:64:1388-91.

54. Lo WT, Wang CC, Lee CM, et al. Successful treatment of multi-resistant Stenotrophomonas maltophilia meningitis with ciprofloxacin in a pre-term infant. Eur J Pediatr 2002;161:680-2.

55. Dalle JH, Auvrignon A, Vassal G, et al. Interaction between methotrexate and ciprofloxacin. J Pediatr Hematol Oncol 2002;24:321-2.

56. Force RW, Hart MC, Plummer SA, et al. Topical ciprofloxacin for otorrhea after tympanostomy tube placement. Arch Otolaryngol Head Neck Surg 1995; 121:880-4

57. Green SD, llunga F, Cheesbrough JS, et al. The treatment of neonatal meningitis due to gram-negative bacilli with ciprofloxacin: evidence of satisfactory penetration into the cerebrospinal fluid. J Infect 1993;26:253-6.

58. Workman MR, Price EH, Bullock P. Salmonella meningitis and multiple cerebral abscesses in an infant. Int J Antimicrob Agents 1999:13:131-2.

59. Johansson A, Berglund L, Gothefors L, et al. Ciprofloxacin for treatment of tularemia in children. Pediatr Infect Dis J 2000;19:449-53.

60. Green S, Tillotson G. Use of ciprofloxacin in developing countries. Pediatr Infect Dis J 1997;16:150-9; discussion 160-2.

61. Angel CA, Green J, Swischuk L, et al. Severe ciprofloxacin-associated pseudomembranous colitis in an eight-year-old child. J Pediatr Surg 2004:39:1590-2.

62. Black A, Redmond AO, Steen HJ, et al. Tolerance and safety of ciprofloxacin in paediatric patients. J Antimicrob Chemother 1990;26(Suppl F):25-9.

63. Gürpinar AN, Balkan E, Kiliç N, et al. The effects of a fluoroquinolone on the growth and development of infants. J Int Med Res 1997;25:302-6.
64. Schaad UB, Sander E, Wedgwood J, et al. Morphologic studies for skeletal toxicity after prolonged ciprofloxacin therapy in two juvenile cystic fibrosis patients. Pediatr Infect Dis J 1992;11:1047-9.

65. Schaad UB, Stoupis C, Wedgwood J, et al. Clinical, radiologic and magnetic resonance monitoring for skeletal toxicity in pediatric patients with cystic fibrosis receiving a three-month course of ciprofloxacin. Pediatr Infect Dis $J$ 1991;10:723-9.

66. Mullen CA, Petropoulos D, Rytting M, et al. Acute reversible arthropathy in a pediatric patient with cancer treated with a short course of ciprofloxacin for febrile neutropenia. J Pediatr Hematol Oncol 1998:20:516-17.

67. Pradhan KM, Arora NK, Jena A, et al. Safety of ciprofloxacin therapy in children: magnetic resonance images, body fluid levels of fluoride and linear growth. Acta Paediatr 1995;84:555-60

68. Chyský V, Kapila K, Hullmann R, et al. Safety of ciprofloxacin in children: worldwide clinical experience based on compassionate use. Emphasis on joint evaluation. Infection 1991;19:289-96.

69. Bendig JW, Kyle PW, Giangrande PL, et al. Two neutropenic patients with multiple resistant Pseudomonas aeruginosa septicaemia treated with ciprofloxacin. J R Soc Med 1987;80:316-17.

70. Park JR, Coughlin J, Hawkins D, et al. Ciprofloxacin and amoxicillin as continuation treatment of febrile neutropenia in pediatric cancer patients. Med Pediatr Oncol 2003;40:93-8.

71. Sarkar S, Singh M, Narang A. Successful treatment of hospital acquired Klebsiella pneumoniae meningitis in a neonate with ciprofloxacin. Indian Pediatr 1993;30:913-14.

72. Singh UK, Sinha RK, Prasad B, et al. Ciprofloxacin in children: is arthropathy a limitation? Indian J Pediatr 2000;67:386-7.

73. Karande S, Kshirsagar NA. Ciprofloxacin use: acute arthropathy and long-term follow up. Indian Pediatr 1996;33:910-16.

74. Hampel B, Hullmann R, Schmidt H. Ciprofloxacin in pediatrics: worldwide clinical experience based on compassionate use - safety report. Pediatr Infect Dis J 1997:16:127-9; discussion 160-2.

75. Bethell DB, Hien TT, Phi LT, et al. Effects on growth of single short courses of fluoroquinolones. Arch Dis Child 1996;74:44-6.

76. Dohar J, Giles W, Roland P, et al. Topical ciprofloxacin/dexamethasone superior to oral amoxicillin/clavulanic acid in acute otitis media with otorrhea through tympanostomy tubes. Pediatrics 2006;118:e561-9

77. Jick S. Ciprofloxacin safety in a pediatric population. Pediatr Infect Dis J 1997:16:130-3: discussion 133-4, 160-2.

78. Thomsen LL, Paerregaard A. Treatment with ciprofloxacin in children with typhoid fever. Scand J Infect Dis 1998;30:355-7.

79. Danisovicová A, Brezina M, Belan S, et al. Magnetic resonance imaging in children receiving quinolones: no evidence of quinolone-induced arthropathy. A multicenter survey. Chemotherapy 1994;40:209-14.

80. Belet N, Haciömeroglu P, Küçüködük S. Ciprofloxacin treatment in newborns with multi-drug-resistant nosocomial Pseudomonas infections. Biol Neonate 2004:85:263-8.

81. Green SD, llunga FM, Numbi A, et al. An open study of ciprofloxacin for the treatment of proven or suspected extra-intestinal salmonellosis in African children: a preliminary report. Adv Antimicrob Antineoplas Chemo 1992;11(Suppl):181-7.

82. Goshen S, Raas-Rothschild A, Lang R. Oral ciprofloxacin in the management of children with chronic suppurative otitis media without cholesteatoma. Adv Antimicrob Antineoplas Chemo 1992;11(Suppl):175-7.

83. Kuhn R, Palmejar A, Kanga J. Tolerability of ciprofloxacin in pediatric patients with cystic fibrosis. Adv Antimicrob Antineoplas Chemo 1992;11(Suppl):269-71

84. Rubio TT. Clinical and laboratory experience with ciprofloxacin in children two to sixteen years of age. Adv Antimicrob Antineoplas Chemo 1992;11(Suppl):151-4.

85. Chotigeat U, Khorana M, Waranawat N. Successful treatment of late onset infection due to multi-drug resistant Acinetobacter Lwoffii in a low birth weight neonate using ciprofloxacin. J Med Assoc Thai 2001;84:910-13

86. Khaneja M, Naprawa J, Kumar A, et al. Successful treatment of late-onset infection due to resistant Klebsiella pneumoniae in an extremely low birth weight infant using ciprofloxacin. J Perinato/ 1999;19:311-14.

87. Khan DM, Bhutta ZA. Ciprofloxacin in multi-resistant infections in childhood: an audit. J Pak Med Assoc 1995;45:147-50.

88. Uppal R, Jhaj R, Malhotra S. Adverse drug reactions to fluoroquinolones at a tertiary care hospital in northern India. J Assoc Physicians India 1998:46:946-7.

89. Wintermeyer SM, Hart MC, Nahata MC. Efficacy of ototopical ciprofloxacin in pediatric patients with otorrhea. Otolaryngol Head Neck Surg 1997;116:450-3

90. Hussey G, Kibel M, Parker N. Ciprofloxacin treatment of multiply drug-resistant extrapulmonary tuberculosis in a child. Pediatr Infect Dis J 1992;11:408-9.

91. Dab I, Desmyttere S, Malfroot A. Repeated use of ciprofloxacin in a pediatric cyctic fibrosis population. Adv Antimicrob Antineoplas Chemo 1992:11(Suppl):143-6. 
92. Pillay T, Pillay DG, Adhikari M, et al. An outbreak of neonatal infection with Acinetobacter linked to contaminated suction catheters. J Hosp Infect 1999:43:299-304.

93. Hacimustafaoglu M, Cil E, Nacarküçük E. Unusual adverse effects of ciprofloxacin: purpuric eruptions and local venospasm. Pediatr Infect Dis $J$ 1995; 14:551-2.

94. Brown NM, Körner RJ, Zollman CE, et al. Ciprofloxacin treatment of bacterial endocarditis involving prosthetic material after cardiac surgery. Arch Dis Child 1997:76:68-9.

95. Rfidah EI, Findlay CA, Beattie TJ. Reversible encephalopathy after intravenous ciprofloxacin therapy. Pediatr Nephrol 1995;9:250-1.

96. Abouesh A, Stone C, Hobbs WR. Antimicrobial-induced mania (antibiomania): a review of spontaneous reports. J Clin Psychopharmacol 2002;22:71-81.

97. Trautmann M, Held T, Ruhnke $\mathrm{M}$, et al. A case of rhinoscleroma cured with ciprofloxacin. Infection 1993;21:403-6.

98. Lotti T, Mirone V, Imbimbo C, et al. Ciprofloxacin in the treatment of urinary tract infections. J Int Med Res 1987;15:240-4.

99. Simpson J, Watson AR, Mellersh A, et al. Typhoid fever, ciprofloxacin, and renal failure. Arch Dis Child 1991;66:1083-4.

100. Davis H, McGoodwin E, Reed TG. Anaphylactoid reactions reported after treatment with ciprofloxacin. Ann Intern Med 1989;111:1041-3.

101. Chalumeau M, Tonnelier S, D'Athis P, et al.; Pediatric Fluoroquinolone Safety Study Investigators. Fluoroquinolone safety in pediatric patients: a prospective, multicenter, comparative cohort study in France. Pediatrics 2003;111:e714-19.

102. Winrow AP, Supramaniam G. Benign intracranial hypertension after ciprofloxacin administration. Arch Dis Child 1990;65:1165-6.

103. Yee CL, Duffy C, Gerbino PG, et al. Tendon or joint disorders in children after treatment with fluoroquinolones or azithromycin. Pediatr Infect Dis $\mathrm{J}$ 2002;21:525-9.

104. Hoppe JE, Dopfer R, Huber S, et al. Eradication of Salmonella dublin in an immunodeficient child by combined use of ceftriaxone and ciprofloxacin after failure of either agent alone. Infection 1989;17:399-400.

105. Valerius NH, Koch C, Høiby N. Prevention of chronic Pseudomonas aeruginosa colonisation in cystic fibrosis by early treatment. Lancet 1991;338:725-6.

106. Gbadoé AD, Dogba A, Dagnra AY, et al. [Acute osteomyelitis in the child with sickle cell disease in a tropical zone: value of oral fluoroquinolones]. Arch Pediatr 2001;8:1305-10.

107. Mishra A, Mishra S, Jaganath G, et al. Acinetobacter sepsis in newborns. Indian Pediatr 1998:35:27-32

108. Milio MC, Campana S. [Use of quinolones in the treatment of Pseudomonas aeruginosa infections in children with cystic fibrosis]. Pediatr Med Chir 1995; 17:53-5
109. Ahmed AS, Khan NZ, Saha SK, et al. Ciprofloxacin treatment in preterm neonates in Bangladesh: lack of effects on growth and development. Pediatr Infect Dis J 2006;25:1137-41.

110. Hata A, Honda Y, Asada K, et al. Mycoplasma hominis meningitis in a neonate: case report and review. J Infect 2008;57:338-43.

111. Ghosh G, Chakraborty S, Ray J, et al. Parenteral ciprofloxacin in persistent diarrhoea in children. J Indian Med Assoc 1995;93:382, 384.

112. Gross RD, Hoffman RO, Lindsay RN. A comparison of ciprofloxacin and tobramycin in bacterial conjunctivitis in children. Clin Pediatr (Phila) 1997;36:435-44.

113. Nejjari N, Benomar S, Lahbabi MS. [Nosocomial infections in neonatal and pediatric intensive care. The appeal of ciprofloxacin]. Arch Pediatr 2000;7:1268-73.

114. Dey SK. Nightmare due to ciprofloxacin in young patients. Indian Pediatr 1995; 32:918-20

115. Odoul F, Le Guellec C, Giraut C, et al. Ciprofloxacin pharmacokinetics in young cystic fibrosis patients after repeated oral doses. Therapie 2001;56:519-24.

116. Dutta S, Chowdhary G, Kumar P, et al. Ciprofloxacin administration to very low birth weight babies has no effect on linear growth in infancy. J Trop Pediatr 2006:52:103-6.

117. Bhutta ZA, Farooqui BJ, Sturm AW. Eradication of a multiple drug resistant Salmonella paratyphi A causing meningitis with ciprofloxacin. J Infect 1992:25:215-19.

118. Sendzik J, Lode H, Stahlmann R. Quinolone-induced arthropathy: an update focusing on new mechanistic and clinical data. Int J Antimicrob Agents 2009;33:194-200.

119. Medrano San Ildefonso M, Mauri Llerda JA, Bruscas Izu C. [Fluoroquinoloneinduced tendon diseases]. An Med Interna 2007;24:227-30.

120. Maurin N. [Fluoroquinolone-induced Achilles tendon rupture]. Dtsch Med Wochenschr 2008;133:241-4

121. Levadoux M, Carli P, Gadea JF, et al. [Repeated rupture of the extensor tendons of the hand due to fluoroquinolones. Apropos of a case]. Ann Chir Main Memb Super 1997; 16:130-3.

122. van der Linden PD, van Puijenbroek EP, Feenstra J, et al. Tendon disorders attributed to fluoroquinolones: a study on 42 spontaneous reports in the period 1988 to 1998. Arthritis Rheum 2001:45:235-9.

123. Menschik M, Neumüller J, Steiner CW, et al. Effects of ciprofloxacin and ofloxacin on adult human cartilage in vitro. Antimicrob Agents Chemother 1997; 41:2562-5

124. von Keutz E, Rühl-Fehlert C, Drommer W, et al. Effects of ciprofloxacin on joint cartilage in immature dogs immediately after dosing and after a 5-month treatment-free period. Arch Toxicol 2004;78:418-24.

125. Mohanasundaram J, Mohanasundaram S. Effect of duration of treatment on ciprofloxacin induced arthropathy in young rats. Indian J Pharmacol 2001;33:100-3 